\title{
La construcció del coneixement sobre el verb en alumnes de $3 r$ i Gè d’educació primària
}

\author{
Mariona Casas i Deseures \\ Universitat Autònoma de Barcelona (GREAL); Universitat de Vic (GRELL), Espanya
}

(Article rebut el 13 de març de 2012; versió final rebuda el 23 d'abril de 2012)

\begin{abstract}
Aquest article explora el coneixement declaratiu i els criteris de reconeixement de la categoria gramatical verb en alumnes de $3 r$ i Gè d'educació primària. La hipòtesi de què parteix és que el verb és una de les nocions lingüístiques més complexes i, per tant, més controvertides com a objecte didàctic. Això fa que els alumnes topin amb dificultats a l'hora de construir aquesta noció. La recerca posa en relleu que mentre el criteri semàntic prima a l'hora de definir el verb, els procediments per reconèixer els verbs en frases o textos són morfològics, de manera que el saber declaratiu no esdevé útil com a estratègia per identificar aquesta categoria. Aquests resultats corroboren estudis anteriors sobre la manca de sistematització en la construcció dels conceptes gramaticals i confirmen la necessitat de replantejar l'ensenyament-aprenentatge del verb.
\end{abstract}

\section{Marc de la recerca}

Les diverses teories lingüístiques coincideixen que el verb és una categoria gramatical complexa, especialment des del punt de vista morfològic. La Nueva gramática de la lengua española, per exemple, descriu el verb com "un repertorio, una serie caracterizada por sus propiedades combinatorias y las informaciones morfológicas que acepta” (2009, p. 43) i La Gramàtica del català contemporani també s'expressa en els mateixos termes: "La complexitat del sistema verbal català se centra actualment en la seva diversitat formal” (Solà, 2002, p. 585). Malgrat que tradicionalment les gramàtiques han descrit les categories gramaticals des de la triple dimensió semàntica, morfològica i sintàctica, des del punt de vista didàctic la construcció del coneixement sobre el verb s'ha reduït a l'àmbit formal, justament en un intent de simplificar-ne la noció (Petit, 2004).

Diverses recerques sobre l'ensenyament-aprenentatge del verb a l'educació primària en l’àmbit francòfon (Roubaud i Touchard, 2004; Quet i Dourojeanni, 2004 ; Vaguer i Lavieu, 2004; Vaguer i Leeman, 2005) coincideixen que cal replantejar-lo des del punt de vista de l'ensenyament-aprenentatge ${ }^{1}$ (Sautot i Lepoire-Duc, 2009; Lusetti, 2008; Eshkol, 2005). Lusetti (2008), per exemple, reivindica que el verb també s’abordi des de les perspectives sintàctica, semàntica i textual, i que es dissenyin dispositius didàctics que tinguin en compte la complexitat de la noció. I Quet i Dourojeanni (2004) coincideixen en la necessitat de desenvolupar "une approche réflexive de la construction de cette classe grammaticale dès l'école élémentaire” (p. 303). 
Des d’una òptica més psicolingüística, Garitte (2004) assenyala que el verb, tot i que apareix en la producció dels primers mots dels infants, no presenta cap especificitat des del punt de vista psicològic. No és, doncs, una noció evident, que aparegui com un saber intuïtiu, sinó que inicialment és concebut com un enllaç que articula l'oració i triga molt a ser considerat paraula plena, portadora de significat (Ferreiro, 1971). L’adquisició d'aquest concepte, doncs, en tant que element que ha de donar compte de les relacions entre les diferents unitats lingüístiques, ha d'evolucionar paral-lelament al desenvolupament de l’activitat metalingüística.

A Catalunya també s’han portat a terme estudis sobre el coneixement del verb, la majoria dels quals centrats a l'educació secundària i en el marc del Grup de Recerca de la UAB sobre Ensenyament i Aprenentatge de Llengües (GREAL), que ha dissenyat i desenvolupat el model de les seqüències didàctiques per aprendre gramàtica (Camps i Zayas, 2006). Fontich (2006), per exemple, va experimentar una seqüència didàctica per a l'ESO sobre la complementació verbal. Aquest estudi partia de la base que cal investigar sobre la construcció dels conceptes gramaticals per saber amb quines dificultats es troben els alumnes per elaborar coneixement metalingüístic, idea que va desenvolupar, també en el marc d'una seqüència didàctica, en l'estudi sobre $L a$ construcció del saber metalingüístic (Fontich, 2010). Macià (2008), en un treball sobre la classificació categorial a secundària, assenyala que no hi ha relació entre el saber declaratiu i els procediments que els alumnes activen per identificar les classes de mots i sosté que les primeres idees gramaticals, apreses durant l'educació primària, “es petrifiquen en el bagatge de l'estudiant, malgrat la seva insuficiència evident” (p. 64). Per això conclou que, a secundària, el coneixement de les quatre grans categories gramaticals (nom, adverbi, verb i adjectiu) no està prou consolidat. Durán (2008) també se centra en secundària, però únicament en la categoria gramatical del verb per explorar les representacions gramaticals i l'activitat metalingüística dels alumnes en relació a aquest concepte. L’autora conclou, com Macià, que els alumnes construeixen la noció a partir de “criteris diversos i de procedència molt heterogènia que s’han anat superposant sense haver-los sistematitzat”, de manera que "aquest fet provoca una separació entre els sabers declaratius i els sabers procedimentals” (Durán, 2008, p. 96). D’aquests estudis se’n desprèn que la descripció lingüística del verb es tradueix, a les aules, en una gramàtica escolar simplificada.

Els continguts d'aprenentatge relacionats amb la categoria gramatical verb que prescriu el marc curricular vigent a l'educació primària ${ }^{2}$ corroboren el que s’ha dit en les línies precedents. El verb és introduït com a categoria gramatical a cicle inicial (juntament amb el nom i l'article), 
mentre que els cicles mitjà i superior se centren en el reconeixement d'aquesta categoria, des del punt de vista dels tres temps verbals primaris (cicle mitjà) i de les seves característiques morfològiques i sintàctiques (cicle superior). Apuntem, doncs, que el currículum d'educació primària és força reduït en relació als continguts d'aprenentatge relacionats amb la categoria gramatical del verb. Tió (2007) justament diu: “M’he endut la impressió de llegir un currículum de llengua sense cap llengua al darrere (...) potser perquè conté una escassíssima terminologia lingüística (tan escassa que gairebé no hi surten paraules com morfologia, fonologia, sintaxi, prosòdia....)" (p. 8).

Pel que fa als llibres de text, que parteixen del marc curricular, també es caracteritzen per presentar el concepte de verb de forma simplificada, com la resta dels continguts gramaticals (Ferrer i López, 1999; Coronas, 2010; Torralba, 2010; Ribas, 2010). Torralba (2010), en una anàlisi sobre el tractament dels conceptes gramaticals en un llibre de text de 6è de primària, observa que el manual no usa termes com morfologia o sintaxi, que creu que ajudarien l'alumne a organitzar el coneixement que va adquirint. L'autora conclou que, per una banda, “queda palesa la necessitat d‘atorgar a la terminologia el pes específic que té en l’ensenyament de la matèria” i, per l'altra, “es manifesta la necessitat, la importància i la urgència de partir d'una gramàtica pedagògica que faciliti la comprensió dels coneixements gramaticals” (2010, p. 56).

El mateix passa a l'educació secundària. Ribas (2010) compara quatre manuals de llengües d'un mateix curs i constata diverses contradiccions en el tractament del verb. L'autora apunta que aquest eclecticisme dels llibres de text "es más bien fruto de una buscada ambigüedad con objetivos comerciales que de una opción didáctica determinada” (2010, p. 71). Per això conclou que "el libro de texto aparece como un objeto que necesita cambios urgentes, al menos por lo que respecta a la enseñanza y al aprendizaje de la gramática” (Op. Cit.). Milian (2010) ho resumeix així: "En la mayoría de nuestras escuelas y manuales se imparte una gramática de recepción, no de producción” (p. 156).

\section{Disseny i metodologia de la investigació}

Aquesta recerca, doncs, s’emmarca en els estudis citats i pretén aportar informació en relació als coneixements declaratiu i procedimental sobre el verb en alumnes d'educació primària. Concretament l'estudi se centra en alumnes de 3r (primer curs de cicle mitjà) i Gè (segon curs de cicle superior) per observar, també, l’evolució en la construcció del concepte al llarg d'aquests dos cicles educatius. 
L’instrument per a la recollida de dades consisteix en el disseny d'una situació didàctica oral, en parelles, fora de l'aula però dins de l'escola, conduïda per la mateixa investigadora. Es desenvolupa amb 43 parelles (19 de 3r i 24 de 6è), de tres escoles diferents de la comarca d’Osona durant els cursos 2009-2010 i 2010-2011. La situació didàctica consta de quatre tasques a partir de la lectura de frases (tasques 1 i 4) o textos (tasques 2 i 3) que junt amb un acompanyament discursiu per part de la investigadora promouen la reflexió dels alumnes (Milian, 2005; Mann, 2011; Mondada, 2002) a l'entorn del verb ${ }^{3}$. Els textos i les frases usats en en aquesta recerca figuren a la taula següent:

Taula 1. Textos i frases de les tasques desenvolupades durant la recerca

\begin{tabular}{|l|l|}
\hline $\begin{array}{l}\text { Tasca 1 } \\
\text { (frases) }\end{array}$ & $\begin{array}{l}\text { Els nens i les nenes canten cançons al pati de l'escola. } \\
\text { Els nens i les nenes cantaven cançons al pati de l'escola. } \\
\text { Els nens i les nenes cantaran cançons al pati de l'escola }\end{array}$ \\
\hline $\begin{array}{l}\text { Tasca } 2 \\
\text { text } \\
\text { narratiu; } \\
\text { diari } \\
\text { personal) }\end{array}$ & $\begin{array}{l}\text { Estimat diari, } \\
\text { Avui no he anat a l'escola perquè em trobo malament. Fa dies que em fa mal la panxa i avui quan } \\
\text { m'he llevat tenia febre. } \\
\text { La mare creu que tinc mal de panxa perquè sempre menjo xocolata, però el metge diu que tinc un } \\
\text { virus. En Pau i la Joana, que van a la mateixa classe que jo, també tenen febre. } \\
\text { M'agrada molt anar a l'escola perquè hi aprenc coses, però ara que estic escrivint aquest diari, } \\
\text { també m'ho passo bé. }\end{array}$ \\
\hline $\begin{array}{l}\text { Tasca 3 } \\
\text { text } \\
\text { descriptiu/ } \\
\text { explicatiu } \\
\text { sobre } \\
\text { animal) }\end{array}$ & $\begin{array}{l}\text { La sargantana és un rèptil que pertany a la família dels lacèrtids. No fa cap mal; es dedica a la } \\
\text { caça de tota mena d'animalets. } \\
\text { Pel bon temps pren el sol per les pedres d'alguns marges o parets i quan veu algú que s'atansa, } \\
\text { s'esmuny amb lleugeresa entre les pedres. } \\
\text { La sargantana té uns ulls menuts que d'en tant en tant obre i tanca. La seva oïda percep la remor } \\
\text { més lleu. S'alimenta de cuques, mosques i altres insectes. }\end{array}$ \\
(frases) 4 & $\begin{array}{l}\text { Al segle XV, Colom descobreix Amèrica (4.1) } \\
\text { Al 1969, l'home arriba a la Lluna (4.2) } \\
\text { Aquestes vacances ens quedem a casa (4.3) } \\
\text { Al programa de la festa he vist que els alumnes de cinquè canten després dels de quart (4.4) }\end{array}$ \\
\hline
\end{tabular}

Des del punt de vista metodològic, totes les converses generades a partir de la situació didàctica s’han enregistrat en àudio, s’han transcrit (notació ortogràfica) i s’han segmentat en episodis en funció de les subpreguntes d’investigació plantejades a cada tasca ${ }^{4}$. En els fragments de les converses que es presenten, els torns iniciats amb la lletra "I" indiquen investigadora; i els iniciats per la resta de lletres corresponen a les inicials dels pseudònims dels alumnes ${ }^{5}$. Les parelles 1 a 19 són de 3r, mentre que de la parella 20 a la 43, de 6è.

En l'apartat següent (desenvolupament i resultats de la recerca) es presenten, en primer lloc, les dades relacionades amb la idea de verb que manifesten les parelles a la tasca 1 , concretament el seu saber declaratiu i l'emergència o no de la paraula verb per designar el concepte (aquests resultats es desglossen en els dos primers subapartats); en segon lloc, es mostren els criteris de reconeixement dels verbs que les parelles usen en les tasques 2, 3 i 4; i, 
finalment, es conclou l'apartat relacionant el saber declaratiu i el reconeixement dels verbs. Les dades es classifiquen d'acord amb els criteris semàntic, morfològic i sintàctic, usats en recerques com les de Roubaud i Touchard (2004) i Durán (2008), entre d’altres. Es parteix de dades quantitatives (classificació per criteris) però el desenvolupament de l'anàlisi és qualitatiu.

\section{Desenvolupament i resultats de la recerca}

El saber declaratiu sobre la categoria gramatical verb i emergència de la paraula "verb”: Davant la pregunta “què és un verb?”, la majoria de les parelles defineixen el verb des del punt de vista semàntic. Aquest percentatge és superior entre les parelles de 3r (57\%) que entre les parelles de 6è (33\%). Si atenem a una possible subclassificació dins del criteri semàntic, un 86\% de les parelles defineixen el verb a partir de la paraula acció (un 75\% de 3r i el 100\% de les de 6è). El criteri morfològic és usat pel 17\% de les parelles, un percentatge lleugerament superior en les parelles de 6è (19\%) que en les de 3r (14\%). I un 14\% del total de les parelles combina el criteri morfològic i el semàntic. No hi ha cap parella de 3r, però, que usi aquest doble criteri (a 6è, representen un $24 \%$ de les parelles). La taula següent mostra un exemple de cada criteri ${ }^{6}$ :

Taula 2. Exemples de respostes per a cada criteri

\begin{tabular}{|l|l|}
\hline \multicolumn{1}{|c|}{ Parella } & Criteris \\
\hline \multicolumn{1}{|c|}{ SEMÀNTICA } \\
\hline $\begin{array}{l}\text { Par. 2 (3r) } \\
\text { G: Gina }\end{array}$ & 21. G: És una acció que fem nosaltres contínuament. \\
\hline $\begin{array}{l}\text { Par. } 29 \text { (6è) } \\
\text { A: Andreu } \\
\text { F: Francesc }\end{array}$ & $\begin{array}{l}\text { 35. A: Un verb és una acció. } \\
\text { corres. Per exemple, un verb d'exemple és córrer. Córrer és un verb perquè és una acció que fas, }\end{array}$ \\
\hline \multicolumn{2}{|c|}{ SEMÀNTICA + MORFOLOGIA } \\
\hline $\begin{array}{l}\text { Par. 20 (6è) } \\
\text { E: Ester } \\
\text { M: Marina }\end{array}$ & \begin{tabular}{l} 
27. E: És una acció. \\
\hline \multicolumn{2}{|c|}{ MORFOLOGIA }
\end{tabular} \\
\hline $\begin{array}{l}\text { Par. 14 (3r) } \\
\text { M: Marc }\end{array}$ & 36. M: Paraules que es canviaven. \\
\hline $\begin{array}{l}\text { Par. 31 (6è) } \\
\text { M: Mila }\end{array}$ & 25. M: És:: eh, és una paraula que hi ha diferents coses: jo cantava, tu cantaves, ell cantava:: \\
\hline
\end{tabular}

Aquests resultats indiquen que el semàntic és el criteri predominant per definir el verb. L’ús prioritari de la paraula acció procediria dels llibres de text, que simplificarien la definició de la noció. El fet que només les parelles de 6è usin el doble criteri podria ser indicatiu que coneixen més d'una estratègia (ja han incorporat l'estratègia formal, d'acord amb el currículum), però que les usen de manera acumulativa, sense capacitat de relacionar-les. 
Pel que fa a l'emergència de la paraula verb, durant la tasca 1 , en què es presenten tres frases que es diferencien únicament per les tres formes verbals ${ }^{7}$, la investigadora demana a les parelles quina mena de paraules són canten, cantaran i cantaven. Les seves respostes es poden classificar segons s’indica a la Taula 3 i s’exemplifica a la Taula 4:

Taula 3. Classificació percentual a la pregunta “Quina mena de paraules són canten, cantaran i cantaven?”

\begin{tabular}{|l|l|l|l|}
\hline Indicador & Parelles 3r & Parelles 6è & Total parelles \\
\hline DEFINICIÓ sense usar la paraula verb & $80 \%$ del total & $20 \%$ del total & $16 \%$ \\
& $33 \%$ de 3r & $5 \%$ de 6è & \\
\hline DEFINICIÓ usant la paraula verb & $22 \%$ del total & $78 \%$ del total & $74 \%$ \\
& $42 \%$ de 3r & $95 \%$ de 6 è & \\
\hline ALTRES (no saben identificar quina mena & $\begin{array}{l}100 \% \text { del total } \\
\text { de paraules són) }\end{array}$ & $\begin{array}{l}0 \% \\
0 \%\end{array}$ & \multirow{2}{*}{$10 \%$} \\
\hline
\end{tabular}

Taula 4. Exemple de respostes segons la Taula 3

\begin{tabular}{|c|c|c|}
\hline Indicador & Parella & Fragment \\
\hline \multirow[t]{2}{*}{$\begin{array}{l}\text { DEFINICIÓ sense } \\
\text { usar la paraula verb }\end{array}$} & $\begin{array}{l}\text { Par. } 6 \text { (3r) } \\
\text { L: Laia } \\
\text { V:Vanesa }\end{array}$ & $\begin{array}{l}\text { 26. L: Una cosa. } \\
\text { 27. I: Una cosa? } \\
\text { 28. L: Una cosa que tu fas. } \\
\text { 29. I: Ah, és una cosa que fas. I què són les coses que fas? Com es diuen? } \\
\text { 30. L: Com-, si dibuixes en una pissarra tu ho fas::: } \\
\text { 31. V: Dibuixes. }\end{array}$ \\
\hline & $\begin{array}{l}\text { Par. } 14 \text { (3r) } \\
\text { M: Marc }\end{array}$ & 28. M: Que canten cançons. Que fan la-la-la-la-la:: \\
\hline \multirow[t]{2}{*}{$\begin{array}{l}\text { DEFINICIÓ usant } \\
\text { la paraula verb }\end{array}$} & $\begin{array}{l}\text { Par. } 8 \text { (3r) } \\
\text { X: Xevi }\end{array}$ & 11. X: Els verbs que fan de present, futur i passat. \\
\hline & $\begin{array}{l}\text { Par. } 27 \text { (6è) } \\
\text { A: Alba }\end{array}$ & $\begin{array}{l}\text { 40. I: Quina mena de paraules són? } \\
\text { 41. A: Jo no n’estic segura:: } \\
\text { 42. I: Digues, digues sense por:: } \\
\text { 43. A: Un verb. } \\
\text { 44. I: Un verb, molt bé. }\end{array}$ \\
\hline
\end{tabular}

Segons es desprèn de la Taula 3, un 74\% de les parelles responen usant la paraula verb, mentre que un $16 \%$ no fa emergir aquesta paraula en la resposta, i un 10\% no sap identificar quina mena de paraules són canten, cantaven i cantaran. Justament aquest $10 \%$ del total correspon a parelles de $3 r$.

En canvi, si ens fixem en les parelles de 6è, no hi ha cap parella que no sàpiga identificar les tres paraules com a verbs. El 95\% ho fa usant la paraula verb, i la resta no fa emergir aquesta paraula.

Aquests resultats podrien indicar que més de la meitat de les parelles de 3r encara no tenen interioritzada la paraula verb (només un $42 \%$ de les parelles de $3 r$ usen aquest mot per referir-se a la noció), motiu pel qual aquesta paraula no emergeix per respondre la pregunta de la investigadora. D’altra banda, si ens fixem en la Taula 4, concretament en els dos exemples de 
parelles de 3r que no fan servir la paraula verb, l'ús d'una onomatopeia (parella 14, torn 28) i d'un exemple (parella 6, torns 30-31) també serien un indicatiu que aquestes parelles no disposen del metallenguatge suficient que els permeti parlar de la classe de paraules que són canten, cantaven i cantaran. Amb tot, manifestarien un coneixement acceptable d'una noció de verb que estaria en procés.

Entre les que sí que usen la paraula verb s’ha exemplificat amb les parelles 8 i 27 justament per mostrar que la parella de 3r (parella 8) presenta una resposta molt més elaborada que la de 6è (parella 27), demostrant que sap que el verb aporta informació temporal.

Relació entre el saber declaratiu i el reconeixement de “canten”, “cantaven” i “cantaran”:En aquest subapartat, observarem quina relació s’estableix entre el coneixement de la noció de verb que manifesten les parelles (saber declaratiu) i la resposta que donen a la pregunta sobre quin tipus de paraules són canten, cantaven i cantaran. Tots dos episodis pertanyen a la mateixa tasca (tasca 1) i en algun cas són consecutius.

Les primeres parelles que s’analitzen són les parelles 1 i 4, totes dues de 3r. En ambdues, en la resposta a la pregunta què és un verb? hi apareix explícitament la referència a l'assignatura de llengua catalana. En aquests exemples s’il-lustra que les parelles no saben respondre la pregunta sobre quina mena de paraules són canten, cantaven i cantaran però sí sobre el saber declaratiu, una al·ludint a la morfologia (parella 4) i l’altra a la semàntica (parella 1).

Taula 5. Manca de relació entre el reconeixement del verb i la seva definició en la tasca 1 en les parelles 4 i 1

\begin{tabular}{|c|c|c|}
\hline & $\begin{array}{l}\text { Quina mena de paraules són canten, cantaran i } \\
\text { cantaven? }\end{array}$ & Què és un verb? \\
\hline $\begin{array}{l}\text { Par. } 4 \text { (3r) } \\
\text { A: Albert } \\
\text { G: Guiu }\end{array}$ & $\begin{array}{l}\text { 30. I: Quina mena de paraula és? Canten, } \\
\text { cantaven, cantaran? Quina mena de paraules són? } \\
\text { 31. A: Mm::: (5) El futur? } \\
\text { 32. I: Quines paraules coneixeu? } \\
\text { 33. G: Música? } \\
\text { 34. A: L'escola? } \\
\text { 35. I: Què és això ((assenyalant les tres } \\
\text { paraules))? Canten, cantaven, cantaran, què és? } \\
\text { 36. G: Mm:: (7) Frases? }\end{array}$ & $\begin{array}{l}\text { 37. I: I us sona què és un verb? } \\
\text { 38. G: Sí. } \\
\text { 39. A: Sí, és lo que estem fent a català. } \\
\text { 40. I: I què és un verb? } \\
\text { 41. G: És un-, és una:: } \\
\text { 42. A: És això: -en, -en, -an. }\end{array}$ \\
\hline $\begin{array}{l}\text { Par.1 (3r) } \\
\text { P: Pere } \\
\text { D: David }\end{array}$ & $\begin{array}{l}\text { 30. P: Són substantius? } \\
\text { 31. I: No:: Un substantiu és un nom, no? Què és } \\
\text { canten, cantaven i cantaran? Què deuen ser? } \\
\text { 32. D: Sí::: ((pensa)) } \\
\text { 33. P: Això ho vam fer a medi:: } \\
\text { 34. D: Sí:: Però és que no me’n recordo dels } \\
\text { noms! } \\
\text { 35. I: Què deu ser? } \\
\text { 36. D: El pas del temps? } \\
\text { 37. I: El pas del temps! Molt bé! Ho vau fer a }\end{array}$ & $\begin{array}{l}\text { 60. D: Ah, sí! Això ho vam fer a català. } \\
\text { 61. I: A::. I què és un verb? Us en } \\
\text { recordeu? } \\
\text { 62. D: Doncs un nom que acompanya:: un } \\
\text { fet:: } \\
\text { 63. P: Una acció:: } \\
\text { 64. I: A veure, que esteu dient coses molt } \\
\text { interessants:: Què dius, David? } \\
\text { 65. D: Que és un fet. } \\
\text { 66. I: I tu Pere? }\end{array}$ \\
\hline
\end{tabular}


medi? I aquestes paraules, però, què són? Hem dit 67. P: És una acció.

que no eren noms:: Què deuen ser, si no són noms?

38. D: Paraules.

39. I: Paraules. Però sabeu com es diuen, aquestes paraules? (4) No ho sabeu, no passa res.

La parella 4 (Taula 5) és incapaç d'identificar les paraules canten, cantaven i cantaran com a verbs (fragment de l'esquerra), però davant la pregunta de la investigadora, que fa emergir la paraula verb, defineix aquesta noció al-ludint a la morfologia, a partir del seu coneixement escolar de l'assignatura de català (tal com expliciten al torn 39, fragment de la dreta). De fet, en realitat en Guiu (G) no sap com definir què és un verb (torn 41), mentre que l'Albert (A) assenyala la terminació de les paraules (sembla que indiqui que el verb és justament això, és a dir, una terminació; torn 42). Resulta curiós que la parella faci al·lusió a la morfologia precisament fixant-se en la terminació de les paraules canten [-en], cantaven [erròniament diuen -en, quan haurien de dir -aven] i cantaran [erròniament diuen - an, quan haurien de dir -aran] i, en canvi, no respongui correctament que canten, cantaven i cantaran són verbs. Aquesta parella també comet més errors de reconeixement de verbs en tasques posteriors. D’altra banda, en relació a la identificació errònia de la segmentació morfològica, semblaria que aquesta parella manifesta una visió restringida de les terminacions verbals (reduïda a les dues últimes lletres). No tindria, doncs, prou interioritzada la morfologia verbal.

La parella 1 (Taula 5) il·lustra el mateix que la parella 4. En efecte, la parella 1 disposa d’un coneixement escolar, també explícitament adquirit a la classe de llengua, que li permet intentar definir què és un verb a través del criteri semàntic i l'ús de la noció d’acció (fragment de la dreta), però aquest coneixement no l'ha pogut aplicar prèviament per identificar les paraules canten, cantaran i cantaven (fragment de l'esquerra). A la conversa per esbrinar quina mena de paraules són no apareix l’al·lusió a l’assignatura de català, sinó a coneixement del medi.

En concret, és interessant l'al·lusió a les assignatures de llengua catalana i de coneixement del medi [natural, social i cultural]. L'anàlisi de totes dues àrees en el currículum d'educació primària evidencia que els continguts de llengua catalana, a cicle mitjà, se centren en el coneixement del verb essencialment des del punt de vista morfològic, mentre que a l'àrea de coneixement del medi social, concretament des de la història, s’aborda el concepte de temps des d'una altra òptica. Així, en aquesta àrea, el currículum explicita que "els coneixements històrics 
de l'educació primària han de permetre a l'alumnat ubicar la seva pròpia història en el temps social i relacionar el passat amb el present i el futur” $\left(2009^{8}\right.$, p. 78).

En altres parelles de 3r també s’evidencia aquesta manca de relació abans esmentada entre la noció de verb que manifesten i el seu saber procedimental:

Taula 6. Manca de relació entre el reconeixement del verb i la seva definició en altres parelles de 3r

\begin{tabular}{|l|l|l|}
\hline & $\begin{array}{l}\text { Quina mena de paraules són canten, cantaran i } \\
\text { cantaven? }\end{array}$ & Què és un verb? \\
\hline $\begin{array}{l}\text { Par. 8 (3r) } \\
\text { X: Xevi } \\
\text { E: Ernest }\end{array}$ & 11. X: Els verbs que fan de present, futur i passat. & 39. E: Sí, és quan fas una acció. \\
\hline $\begin{array}{l}\text { Par. 9 (3r) } \\
\text { B: Bea }\end{array}$ & $\begin{array}{l}\text { 27. I. I com ho saps, que són verbs? } \\
\text { 28. B: Perquè canten, cantaran i cantaven és igual. }\end{array}$ & 30. B: Una acció. \\
& & \\
\hline
\end{tabular}

La parella 8 (Taula 6, fragment de l'esquerra), per exemple, ja hem vist que feia emergir la paraula verb (Taula 4) i la usava en relació als tres temps primaris, indicant que canten, cantaran i cantaven són "els verbs que fan de present [canten], de futur [cantaran] i de passat [cantaven]. Aquesta resposta indicaria un bon grau de coneixement procedimental sobre el verb des del punt de vista de la flexió temporal, però aquest saber no estaria connectat amb el saber declaratiu, perquè la resposta del saber declaratiu és purament semàntica: "Una acció” (fragment de la dreta).

El mateix passa amb la parella 9 (Taula 6, fragment de l'esquerra), que usa una estratègia morfològica en el coneixement procedimental, però la resposta al saber declaratiu també és semàntica: "Una acció” (fragment de la dreta). Aquesta parella encara no disposaria de prou metallenguatge per parlar sobre llengua. Certament, semblaria que quan la Bea (B) diu que “canten, cantaran i cantaven és igual” (torn 28) en realitat voldria estar dient que aquestes tres formes verbals són un mateix verb i, per il·lustrar-ho, posa l'exemple de la conjugació de les persones gramaticals del present (fent, també, la concordança sintàctica amb els pronoms personals). L’ús de l'exemple no deixa de ser una manera de mostrar, per una banda, la manca de terminologia, i, per l'altra, que la parella té certs coneixements sobre el verb des del punt de vista morfològic (apel-la -sense identificar-los ni designar-los- als morfemes de persona i de temps) però que aquests coneixements no estarien prou integrats.

Un cas diferent és el de la parella 7 (Taula 7), en què s'estableix una mena de cercle viciós entre la resposta sobre el reconeixement de canten, cantaven i cantaran (fragment de l'esquerra) i el coneixement que manifesten sobre la noció de verb (fragment de la dreta). 
Taula 7. Cercle viciós entre el reconeixement del verb i la seva definició la parella 7

\begin{tabular}{|l|l|l|}
\hline & $\begin{array}{l}\text { Quina mena de paraules són canten, cantaran i } \\
\text { cantaven? }\end{array}$ & Què és un verb? \\
\hline Par.7 (3r) & 18. I: Molt bé. I aquestes paraules, què són? & 24. I: Molt bé. Es diuen verbs. I què és un \\
S: Sílvia & 19. S: Ve de cantar. & verb? \\
M: Marta & 20. I: Ah, molt bé. I què és cantar? & 25. Les accions que fem. \\
& $\begin{array}{l}\text { 21. S: Són les accions que fem. } \\
\text { 22. I: Molt bé. } \\
\text { 23. M: Les accions que fem es diuen verbs. }\end{array}$ \\
\hline
\end{tabular}

En aquesta parella, la Sílvia (S) reconeixeria que canten, cantaven i cantaran correspondria a tres paraules associades al verb cantar (torn 19) i tot seguit, preguntada per la definició de cantar, diu que "són les accions que fem” (torn 21). És a dir, relaciona les formes verbals amb l'infinitiu cantar (això és un argument morfològic, tot i que vague, en el sentit que no fa emergir la paraula infinitiu) i diu que és una acció (argument semàntic, que també, en certa manera, es podria interpretar des del punt de vista sintàctic, per l'agentivitat). La Marta (M) expandeix aquesta resposta afegint que “les accions que fem es diuen verbs” (torn 23). És a dir, la Marta fa emergir la paraula verb després que la Sílvia l’hagi conceptualitzat morfològicament a través de l’infinitiu i definit semànticament a través de la paraula acció. Per això, quan, al torn següent, la investigadora demana què és un verb (fragment de la dreta, torn 24), la resposta torna a ser "les accions que fem” (torn 25). D’alguna manera, semblaria que la parella ha anat teixint la noció de verb (evocant la definició escolar de verb com a acció), a partir de l'exemple de canten, cantaven i cantaran.

Recapitulant, fins ara s’han presentat els resultats relacionats amb la tasca 1 , en què s'exploren, per un banda, el saber declaratiu sobre la categoria gramatical verb i l'emergència de la paraula verb per definir la noció; i, per l'altra, les relacions entre aquests dos tipus de respostes. S’ha vist que el criteri semàntic prima per definir el verb i que més de la meitat de les parelles de 3r encara no tenen interioritzada la paraula verb. I també s’ha mostrat la manca de relació entre el coneixement sobre el verb que manifesten i la identificació de canten, cantaven i cantaran com a verbs.

Criteris de reconeixement del verb als textos de les tasques 2 i 3 i a les frases de la tasca 4: Les tasques 2 i 3 giren a l'entorn d'un text narratiu i d'un text descriptiu/explicatiu, respectivament ${ }^{9}$. En totes dues tasques, les parelles han estat requerides per identificar verbs dels textos i justificar per què creuen que les paraules que han marcat són verbs. El criteri morfològic és el predominant. Tot seguit es presenten alguns exemples de totes dues tasques: 
Taula 8. Exemple de reconeixement dels verbs de la tasca 2 (criteri morfològic) en la parella 7

\begin{tabular}{|l|l|}
\hline Par. 7 (3r) & 71. I: Com ho sabeu quan una paraula és un verb? \\
& 72. S: Perquè ho hem fet a català. Per exemple, jo trobo, ell troba, nosaltres trobem, vosaltres \\
trobeu i ells troben. I així és el verb. & 73. S: Ens ha dit la professora que si no sabem si és un verb o no, provem això. \\
& 74. I: I això funciona? \\
75. S: Sí. Per exemple, ara en dic una de malament. Per exemple, quan. Jo no sé si és un verb i \\
faig: jo quan, tu quan, ell quan:: No sona bé. Dic que no és un verb. \\
76. I: Molt bé. \\
77. S: Si dic trobo, jo dic, jo trobo, tu trobes, ell troba. Sí que sona bé. És un verb. ((van buscant \\
els verbs, en veu baixa)) \\
78. I: No ho feu en veu baixa, ja ho podeu dir alt. \\
79. S: És que estic provant si és un verb. \\
80. I: Quina paraula? \\
81. S: Creu. Jo crec, tu creus, ell creu, nosaltres creiem, vosaltres creieu i ells creuen. Sí que és un \\
verb.
\end{tabular}

La parella 7 (Taula 8) fa al·lusió a l'assignatura de català (com ho havien fet les parelles 1 i 4 a la tasca 1, Taula 5), de manera que explicita que es tracta d'una estratègia escolar adquirida a la classe de llengua (torns 72 i 73). Efectivament, una membre de la parella mostra que sap reconèixer el verb a través del criteri morfològic (torn 72), concretament conjugant les persones gramaticals del temps verbal del present i posteriorment explica com porta a terme aquesta estratègia: "Ens ha dit la professora que si no sabem si és un verb o no, provem això” (torn 73). La investigadora demana si aquesta estratègia els funciona i aleshores l'alumna diu que sí. Aquesta alumna demostraria saber usar aquesta estratègia escolar, perquè intencionadament escull una paraula que no és verb (quan, torn 75), per aplicar-la i concloure que no ho és.

Si atenem al tipus de criteris morfològics, l’estratègia majoritària que usen les parelles és la conjugació de la persona gramatical (morfema de persona, com hem vist en l'exemple anterior, Taula 8), però també apareix la conjugació dels tres temps verbals primaris (flexió de temps) i la formulació de l'infinitiu (aquesta última estratègia només, però, a 6è). A la taula següent es mostra un exemple d'aquests dos últims criteris, amb les parelles 12 i 39, respectivament: 
Taula 9. Exemple de fragments de la tasca 3 d'ús de diferents criteris morfològics

\begin{tabular}{|l|l|}
\hline $\begin{array}{l}\text { Par.12 (3r) } \\
\text { C: Cristina } \\
\text { A: Anna }\end{array}$ & $\begin{array}{l}\text { 61. C: Obre i tanca. Perquè obria, obre i obrirà. } \\
\text { 62. I tancava, tanca i tancarà. }\end{array}$ \\
\hline $\begin{array}{l}\text { Par. } 39 \text { (6è) } \\
\text { B: Bibiana }\end{array}$ & $\begin{array}{l}\text { 82. I: Ah, molt bé. Fixeu-vos en aquesta frase: “La sargantana té uns ulls menuts”. Hi ha verb en } \\
\text { aquesta frase? }\end{array}$ \\
& $\begin{array}{l}\text { 83. B: Té. } \\
\text { 84. I: I com ho saps, que és un verb, Bibiana? } \\
\text { 85. B: Perquè ve de tenir. }\end{array}$ \\
\hline
\end{tabular}

Precisament, si ens fixem en el procés d’identificació d'alguns dels verbs, observarem que algunes parelles apliquen malament l'estratègia morfològica o l'apliquen però no els funciona. Tot seguit es comenten dos fragments de dues parelles de 3r (les parelles 9 i 15).

La parella 9 (Taula 10) al llarg de la tasca 2 aplica reiteradament l'estratègia de conjugar a partir del morfema de persona. El problema és que només li funciona en tres ocasions. A la resta de casos, aplica malament l'estratègia, confonent el verb per tot el predicat o pel substantiu que el complementa (com en el cas del fragment mostrat, amb febre o escola, que són el complement directe i el complement circumstancial, respectivament).

Taula 10. Identificació errònia dels verbs de la tasca 2 en la parella 9

\begin{tabular}{|l|l|}
\hline Par. 9 (3r) & 89. I: On hi ha un verb? \\
B: Bea & 90. B: A l'escola. \\
& 91. I: Per què? \\
& 92. B: Perquè jo vaig a l'escola, tu vas a l'escola, ell va a l'escola, nosaltres anem a l'escola, vosaltres \\
& aneu a l'escola i ells o elles van a l'escola. \\
& 93. I: Per tant, el verb, on és? \\
& 94. B: A l'escola. \\
& (...) \\
& 120. I: Febre? Febre també és un verb? \\
121. B: Sí. Tu tens febre, nosaltres tenim febre, ells o elles tenen febre.
\end{tabular}

Pel que fa a la parella 15 (Taula 11), semblaria que aplica coneixements sobre la flexió nominal i no pas la flexió verbal, perquè el que fa és canviar el nombre de dos substantius: pedres i sargantana. La parella s’aferra a un argument morfològic, però confon la morfologia nominal i la verbal.

Taula 11. Identificació errònia dels verbs de la tasca 3 en la parella 15

\begin{tabular}{|l|l|}
\hline Par. $15(3 r)$ & 15. I: Ah, a veure, abans ja us ho he demanat. Sabeu què és un verb? \\
A: Aina & 16. A: Paraules que es pot fer després més llarga. \\
J: Jan & 17. I: Pots buscar si hi ha algun verb, aquí? \\
& 18. A: Pedres i pedretes. \\
& 19. I: Per què? (5) Ah, perquè es pot allargar? \\
& 20. A: Sí. \\
& 21. I: Què més? \\
& 22. Sargantana i sargantanes. \\
\hline
\end{tabular}


Pel que fa a la tasca 4, està formada per quatre frases i les parelles han de respondre, a cadascuna $^{10}$, la pregunta següent: "Hi ha verb en aquesta frase?”. En el reconeixement del verb, el criteri morfològic també predomina per sobre del semàntic en totes les tasques, llevat de la 4.1. A la taula següent es presenta un exemple del criteri semàntic.

Taula 12. Exemple de resposta de criteri semàntic (frase 4.1: "Al segle XV, Colom descobreix Amèrica”)

\begin{tabular}{|l|ll|}
\hline Par.19 & 7. & I: Hi ha verb en aquesta frase? \\
(3r) & 8. & O: (17) Sí. \\
O: Òscar & 9. & I: On és el verb? \\
& 10. O: Descobreix. \\
& $\begin{array}{l}\text { 11. I: I com ho saps que és un verb, això, Òscar? } \\
\text { 12. O: Perquè (6) perquè (5) és una cosa que passa. }\end{array}$ \\
\hline
\end{tabular}

En aquest subapartat, però, ens fixarem en algunes errades o confusions en el procés d’identificació dels verbs. La parella 17 (Taula 13) s’equivoca a la tasca 4.2. per la mateixa raó que hem vist que ho feia la parella 15 (Taula 11). Totes dues són de 3r.

Taula 13. Identificació errònia dels verbs de la frase 4.2 ( “Al 1969, l’home arriba a la Lluna”) en la parella 17

\begin{tabular}{|l|l|}
\hline Par.17 (3r) & 9. I: Hi ha verb en aquesta frase? \\
A: Abel & 10. A: (5) L'home. \\
G: Gerard & 11. I: Per què home és un verb? \\
& $\begin{array}{l}\text { 12. A: Perquè hi ha home, homes- } \\
\text { 13. G: Dones, fills- }\end{array}$ \\
& 14. A: Home i homes. \\
\hline
\end{tabular}

A la tasca 4.3, en canvi, la confusió ve generada per la paraula aquestes (la frase és “aquestes vacances ens quedem a casa”). La confusió podria estar vinculada al fet que el demostratiu és un marcador temporal (díctic de temps) i, per tant, les parelles el confondrien amb el verb, que també expressa temps ${ }^{11}$. Tot seguit es presenta un exemple de la parella 29 (Taula 14), que es confon inicialment però que al llarg de la conversa repara l'errada.

Taula 14. Parella que identifica inicialment com a verb el díctic temporal de la frase 4.3

\begin{tabular}{|l|l|}
\hline Par. 29 (6è) & $\begin{array}{l}\text { 27. A: (...) O sigui, si la frase està escrita correctament i no hi ha cap error, vol dir que } \\
\text { A: Andreu }\end{array}$ \\
F: Francesc en present, perquè els dos verbs són en present. \\
\end{tabular}

En aquesta parella 29, l’Andreu (A) inicialment identifica aquestes com a verb, “del verb aquest” (torn 29), però rectifica immediatament. Aquesta parella indica tenir domini de la terminologia, perquè malgrat aquesta confusió, en Francesc $(\mathrm{F})$ corregeix el seu company i diu que aquestes és 
un demostratiu (torn 32). Per tant, sembla que té força clara la classificació de les categories gramaticals.

En resum, doncs, a les tasques 2, 3 i 4 la majoria de les parelles reconeixen els verbs a partir del criteri morfològic, sobretot a través de la conjugació de la persona gramatical. També s'han vist exemples de parelles que apliquen malament l'estratègia $i$, per tant, erren en la identificació dels verbs. El darrer fragment il-lustra un exemple reeixit de reconeixement de les categories gramaticals.

Relació entre el saber declaratiu (tasca 1) i el reconeixement dels verbs a les tasques 2, 3 i 4: Aquest subapartat relaciona el coneixement sobre el verb que han manifestat les parelles a la tasca 1 i els criteris per reconèixer els verbs a les tasques 2, 3 i 4. El creuament de les respostes indica que pràcticament no es poden establir relacions entre el saber declaratiu i els criteris d’identificació del verb: és a dir, els procediments per reconèixer un verb tenen poc a veure (o no tenen res a veure) amb la noció del concepte que han manifestat les parelles (la definició de verb). Vegem-ho amb un exemple a la taula següent: la parella 7, de 3r, defineix semànticament el verb a la tasca 1 (Taula 15, fragment de l'esquerra), però en un cercle viciós (com ja s’ha comentat a partir de la Taula 7), mentre que a la tasca 2 (fragment de la dreta) manifesta explícitament que coneix i que sap aplicar l'estratègia morfològica per identificar-lo (ja s’ha vist a la Taula 8). Així doncs, no s’establiria cap connexió entre tots dos fragments. Recordem-ho:

Taula 15. Fragment de la parella 7 sobre la manca de relació entre la tasca 1 i la tasca 2

\begin{tabular}{|l|l|l|}
\hline & Tasca 1 (extret de Taula 7) & Tasca 2 (extret de Taula 8) \\
\hline Par.7 (3r) & 24. I: (...) I què és un verb? & $\begin{array}{l}\text { 71. I: Com ho sabeu quan una paraula és un verb? } \\
\text { M: Marta }\end{array}$ \\
$\begin{array}{l}\text { S: Síliva } \\
\text { 25. Mes accions que fem. }\end{array}$ & $\begin{array}{l}\text { 72. S: Perquè ho hem fet a català. Per exemple, jo trobo, ell } \\
\text { troba, nosaltres trobem, vosaltres trobeu i ells troben. I així } \\
\text { és el verb. }\end{array}$ \\
\hline
\end{tabular}

En canvi, en algunes parelles de 6è sí que es podria establir certa relació. És el cas, per exemple, de la parella 38 (taula següent), en què s’observa que les respostes sobre el saber declaratiu (Taula 16, tasca 1) i sobre el procediment per reconèixer els verbs (Taula 16, Tasca 3) estan vinculades.

Taula 16. Fragment de la parella 38 sobre la relació entre la tasca 1 i la tasca 3

\begin{tabular}{|l|l|l|}
\hline & Tasca 1 & Tasca 3 \\
\hline Par. 38 (6è) & 34. M: Són paraules que les fem & 22. I: (...) Com ho podem saber si hi ha un verb o no? \\
M: Mireia & nosaltres. & 23. F: Mm:: per exemple, jugar és un verb. Perquè tu \\
F: Fatija & & ho pots fer. \\
& & 24. M: Sí, si tu ho pots fer_ \\
& & 25. F:_És que és un verb. \\
\hline
\end{tabular}


De fet, la Fatija (F) posa jugar com a exemple de verb (torn 23, fragment de la dreta) i ho justifica usant el mateix argument que la resposta de la Mireia (M) a la tasca 1 (torn 34, fragment de l'esquerra). Per tant, les alumnes entendrien el verb des d'un punt de vista sintàctic (és a dir, en destaquen l'agentivitat). Aquest exemple, a més, mostra un grau de coneixement del concepte verb relacionat amb la noció d’acció.

Sobre la relació entre la tasca 1 i la tasca 4 es mostra la parella 31 (Taula 17), de 6è, que usa el criteri morfològic tant per definir el verb com per reconèixer-lo. A més, també ho fa a la tasca 3, de manera que l'exemple mostraria coherència en l'ús del criteri al llarg de les tasques. Vegem-ho:

Taula 17. Fragments de la parella 31 que indiquen coherència de criteri entre les tasques 1 , 3 i 4.4

\begin{tabular}{|c|c|c|c|}
\hline Par. & Tasca 1 & Tasca 3 & Tasca 4.4 \\
\hline $\begin{array}{l}31 \text { (6è) } \\
\text { M: Mila } \\
\text { L: Laura }\end{array}$ & $\begin{array}{l}\text { 22. M: És:: eh, és una paraula } \\
\text { que hi ha diferents coses: jo } \\
\text { cantava, tu cantaves, ell } \\
\text { cantava:: } \\
\text { 23. I: Així doncs, què fa que } \\
\text { sigui diferent? Dieu que és el } \\
\text { mateix verb però que són } \\
\text { paraules diferents. Què voleu } \\
\text { dir? } \\
\text { 24. L: La terminació. } \\
\text { 25. I: I què és la terminació? } \\
\text { 26. L: La::: bueno, com acaben } \\
\text { les paraules. } \\
\text { 27. I: D’acord. I podeu marcar } \\
\text { quines terminacions tenen } \\
\text { aquestes paraules? ((Marquen } \\
\text {-en, -aran, -aven). }\end{array}$ & $\begin{array}{l}\text { 69. I: Com ho sabeu quan } \\
\text { una paraula és un verb o } \\
\text { no? } \\
\text { 70. M: Perquè miro, o } \\
\text { sigui::: } \\
\text { 71. L: Perquè la pots posar } \\
\text { en present, en passat o } \\
\text { en futur. } \\
\text { 72. I: I la pots posar aquesta } \\
\text { paraula, lleugeresa, en } \\
\text { present, en passat i en } \\
\text { futur? } \\
\text { 73. L: Jo::: lleugeresa, ell:: } \\
\text { no, no:: }\end{array}$ & $\begin{array}{l}\text { 38. I: I què passa amb } \\
\text { després? És un verb? } \\
\text { Com ho podem saber } \\
\text { si és un verb o no és } \\
\text { un verb? } \\
\text { 39. L: No, no és un verb. } \\
\text { 40. M: Ells després:: no, } \\
\text { no és un verb ((riuen)) }\end{array}$ \\
\hline
\end{tabular}

Si ens fixem en la taula anterior, a la tasca 1 (fragment de l'esquerra) la parella 31 usa un criteri morfològic (conjugació de la persona gramatical, torn 22) i és l'única parella que fa emergir la paraula terminació (torn 24), evidenciant que coneix alguns conceptes morfològics (terminació és “com acaben les paraules”, torn 26). La definició de verb portaria la parella a reconèixer que canten, cantaven i cantaran són verbs i en marcarien, efectivament, la terminació (torn 27), tot i que, en aquest cas, és la marca de temps, no de persona, que havia estat l'estratègia usada per definir el verb al torn 22. Justament, a les tasques 3 (fragment del mig) i 4.4 (fragment de la dreta) la parella usa aquesta mateixa estratègia i ho fa per desestimar que dues paraules (lleugeresa i després) siguin verbs. De totes maneres, cal destacar que a la tasca 3, l'explicació de l'estratègia no coincideix amb la seva aplicació, ja que l'explicació té a veure amb la marca de 
temps (el que han marcat al torn 27 de la tasca 1, per a canten, cantaven i cantaran) mentre que la prova que fan per saber si lleugeresa és un verb o no té a veure amb la conjugació de les persones gramaticals, que és la mateixa prova que usen a la tasca 3 (torn 73, i la que també havien fet servit per definir el verb a la tasca 1, torn 22). De nou, aquesta parella posa en relleu que disposa d'un cert coneixement morfològic sobre el verb però que no està del tot endreçat (fet que es manifesta en la confusió entre l'estratègia de conjugar les persones i els temps gramaticals).

A manera de recapitulació, en aquest subapartat hem constatat que hi ha algunes parelles de 6è en què el saber declaratiu i el procediment per reconèixer els verbs estan connectats, però són casos poc freqüents. En general, no hi ha relació entre un i altre coneixement. A més, si relacionéssim els fragments de les parelles que cometen errors en la identificació dels verbs en algunes de les tasques amb la resposta que ofereixen sobre la definició de verb ${ }^{12}$, també constataríem que les parelles no apliquen el saber declaratiu, és a dir, que la definició no és útil per al reconeixement de la noció.

\section{Conclusions}

A propòsit dels resultats mostrats en aquest article, apuntem algunes conclusions que vinculen la investigació amb altres estudis sobre la construcció dels conceptes gramaticals dels alumnes (Camps i altres, 2001; Camps i Fontich, 2003; Notario, 2000; Macià, 2008) i especialment sobre el verb (Eshkol, 2005; Durán, 2008). En concret, la present recerca aporta informació en relació al coneixement del verb en alumnes de primària a Catalunya i comparteix amb treballs precedents la premissa que conèixer les dificultat amb què topen els alumnes és el primer pas per replantejar l'ensenyament-aprenentatge de la gramàtica, amb l'objectiu d'articular més eficaçment la reflexió gramatical i l’ús de la llengua. A manera de recapitulació, doncs, en aquest apartat es relacionen els resultats més rellevants que s'han presentat al llarg de l'article amb algunes d'aquestes investigacions.

Quant al saber declaratiu sobre el verb, s’ha vist que el criteri semàntic prima per davant del morfològic i l'ús de la paraula acció en caracteritza la definició. Durán (2008), en la seva recerca amb alumnes de secundària, també conclou que el criteri semàntic és el que pesa més per definir el verb (p.58). De fet, Macià (2008) indica que identificar el verb amb una acció és una simplificació de la noció des del punt de vista semàntic, que es genera a l'educació primària i que es perpetua fins a l’educació secundària: 
Prevalen les definicions nocionals tradicionals de les classes de mots: encara avui molts estudiants arriben a secundària amb la idea que el nom designa "una persona, animal o cosa”, el verb expressa “una acció” i l’adjectiu, “una qualitat del nom”, definicions que no es corresponen prou amb la realitat lingüística. (Macià, 2008, p. 63)

Justament perquè la definició semàntica esdevé massa simple, Eshkol (2005) assenyala que l'escola, a França (però també a Catalunya), opta per tractar el verb essencialment des del punt de vista morfològic:

Définir le verbe par le sens en disant que c'est un mot qui exprime une action parait le plus simple -c'est une définition traditionnelle souvent reprise par les manuels scolaires (...) Enfin, il est difficile de définir les verbes par leur sens (...) C’est pourquoi il est préférable de les identifier par des critères formels et d'abandonner les critères de sens. (p. 22)

Aquesta podria ser una raó per la qual s’explicaria que el criteri formal és més usat per alumnes de 6è que de 3r. L'enfocament formalista estaria més integrat en els alumnes de cicle superior que de cicle mitjà, d'acord amb el desplegament del currículum.

Pel que fa a l'emergència de la paraula verb, de la recerca se'n desprenen diferències importants entre les parelles de 6è i 3r, en el sentit que el 95\% de les parelles de 6è usen la paraula verb per referir-se a aquesta categoria gramatical, mentre que les de 3r són menys de la meitat (42\%). En aquest sentit, doncs, es pot dir que les parelles de 6è ja etiqueten el concepte verb, és a dir, en diuen el nom, de manera que això indicaria que tenen consolidada una de les fases de construcció de la noció (Eshkol, 2005, p. 28). Tot i així, també hem observat que entre les parelles que fan emergir la paraula verb, a 3r també hi ha exemples que demostren conèixer algunes de les propietats de la noció.

D’altra banda, hem vist exemples de parelles de $3 r$ en què el coneixement escolar declaratiu sobre el verb no era útil com a estratègia per reconèixer que determinades paraules pertanyien, justament, a aquesta categoria gramatical. Trobem, doncs, que, tal com diu Macià (2008), el saber declaratiu sovint és purament memorístic. Justament algunes parelles evoquen l'assignatura de coneixement del medi a l'hora de parlar del verb. Amb aquesta constatació insinuaríem que potser podria replantejar-se l'ensenyament-aprenentatge del verb i, més concretament, dels temps verbals, des de la interdisciplinarietat curricular ${ }^{13}$.

Pel que fa als criteris per reconèixer els verbs, hem vist que el morfològic és el majoritari (el semàntic ho era des del punt de vista declaratiu) i l'estratègia més usada és la de conjugar la persona gramatical, seguida de la flexió de temps. Aquestes dades també coincideixen amb les de Durán (2008, p.64) a secundària. D’altra banda, la majoria d'errades dels alumnes s’associen al criteri morfològic. Això corroboraria, d'acord amb Macià, una dinàmica de "procediments 
automatizats i universalitzats a totes les ocurrències d'un mot i, a més a més, aplicats de vegades descontextualitzant l'ítem” (Macià, 2008, p. 70). Quet i Dourojeanni (2004) també assenyalen que els procediments estereotipats condueixen els alumnes a errar perquè no permeten que reflexionin sobre la noció que estan identificant:

Les manipulations enseignées qu'il s'agisse de conjuguer, de mettre un pronom personnel devant, ou d'utiliser le présentatif ne sont jamais pratiquées de manière convergente (...) Ces conduites mécaniques ne sont liées à aucune réflexion sur la langue: elles peuvent permettre de repérer le verbe dans une phrase, et elles contribuent peut-étre, à la construction d'une intuition linguistique (stéréotypes morphosyntaxiques, syntaxiques ou sémantiques) mais sans aucune distance réflexive sur les unités ou les matériaux manipulés. (Quet i Dourojeanni, 2004, p. 36)

En dues parelles de 3r justament hem vist la confusió que generava la flexió en la identificació de la categoria gramatical (confonien substantius per verbs perquè els alumnes desplegaven el morfema nominal de nombre). Creiem que un ensenyament gramatical sistematitzat hauria de permetre a l'alumne evitar aquest tipus d'errades, perquè la construcció dels coneixements gramaticals s’organitzaria de forma significativa. Torralba (2010) ho exemplifica així:

Quan [a un alumne] se li ensenyés la flexió verbal, podria relacionar aquesta informació nova amb la que ja coneix sobre la flexió nominal, i sabria que tot plegat es tracta d'aprendre els mecanismes de la llengua sobre la formació de mots o paraules. (Torralba, 2010, p. 47)

Finalment també hem vist que no s’estableix relació entre els criteris d’identificació del verb i la seva definició (Durán, 2008), corroborant estudis similars sobre altres categories gramaticals (Notario, 2000; Camps i altres, 2001). És a dir, la definició semàntica de verb, la que apareix amb més freqüència als llibres de text, no ajuda a saber reconèixer aquesta noció. Amb tot, que el saber declaratiu (definició) no sigui operatiu, no vol dir que no sigui necessari per construir la noció (Eshkol, 2005). Ruiz Bikandi (2010) subratlla que "no hay un buen conocimiento del objeto si no se es capaz de nombrarlo con propiedad al hablar de él” (p.45) ${ }^{14}$.

Per acabar, a manera de recapitulació, apuntarem algunes diferències observades entre les parelles de $3 r$ i de 6è. En relació al saber declaratiu sobre el verb, ja hem vist que hi ha diferències, en el sentit que les parelles de 6è usen més el criteri morfològic que no pas les de 3r a l'hora de definir el concepte verb. Destacàvem, també, que no hi havia cap parella de 3r que usés el doble criteri semàntic i morfològic.

Brossard i Lambelin (1985) sostenen, justament, que l'ús de diversos criteris ajuda a construir un coneixement de la noció més ajustat a la seva complexitat, però en el cas d’aquesta recerca, no sembla que es pugui demostrar. En tot cas, hem observat que les parelles de 6è 
coneixen diversos criteris (sobretot semàntic i morfològic) però això no vol dir que els integrin, sinó que simplement els acumulen (en la majoria de casos, la confluència de criteris vindria donada perquè un membre n'usa un, i l'altre, un altre). D’altra banda, sobre la paraula verb, ja hem vist que més de la meitat de les parelles de 3r encara no han fet emergir aquest mot per etiquetar la categoria gramatical, mentre que a 6è, sí.

Pel que fa als procediments per identificar els verbs, no s’observen diferències entre $3 \mathrm{r}$ i 6è en l'ús dels criteris, ja que globalment el criteri morfològic és més usat que no pas el semàntic. Amb tot, si ens fixem en les errades, com hem vist, les parelles de 3r erren més que les de 6è. Semblaria, doncs, que el criteri morfològic de reconeixement de la categoria gramatical verb estaria més interioritzat a les parelles de 6è (probablement com a conseqüència del treball morfològic a l'aula).

Respecte a les diferències en la relació entre el saber declaratiu i el procedimental a 3r i 6è, apuntem la següent constatació: les parelles de 6è, com que saben posar nom a la categoria gramatical i usen més el criteri morfològic per definir el verb que no pas les parelles de 3r, establirien algunes connexions entre el saber declaratiu i els processos de reconeixement d’aquesta noció (que essencialment són morfològics). Pel que fa a l’ús del criteris morfològics, Macià (2008) assenyala que seria un signe de “maduració de l’alumnat”, com també ho seria “la disminució de l’argumentació semàntica (..), més lligada a l'aproximació natural de l’alumne/a envers la llengua (vista d'entrada com a vehicle de significats) i, alhora, reforçada per les definicions nocionals tradicionals” (p. 69).

En qualsevol cas, entenem que l'aproximació morfològica tampoc seria suficient per abordar la noció de verb com a objecte didàctic, sinó que s’hauria de desplegar en totes les seves dimensions (Sautot i Lepoire-Duc, 2009; Gourdet, 2010; Hamon, 2005). I més enllà del verb, subscrivim el que diu Ribas en relació a l'ensenyament-aprenentatge de la gramàtica:

La gramática pedagógica o escolar (...) debería concebirse como un punto crucial en el complejo proceso de transposición didáctica que sufren los contenidos curriculares desde que se elaboran en el marco de cada ciencia de referencia hasta que son efectivamente aprendidos por los alumnos y alumnas. (Ribas, 2010, p. 57)

\section{Referències bibliogràfiques}

Brossard, M., \& Lambelin, G. (1985). Problèmes posés par l'acquisition de quelques notions grammaticales. Revue française de pédagogie, 71, 23-28.

Camps, A., Milian, M., Guasch, O., Pérez, F., Ribas, T., \& Castelló, M. (2001). Los conceptos gramaticales de los alumnos de secundaria: el pronombre personal. A A. Camps (coord.), 
El aula como espacio de investigación y reflexión. Investigaciones en Didáctica de la Lengua (pp. 161-180). Barcelona: Editorial Graó.

Camps, A., \& Fontich, X. (2003). La construcció del coneixement gramatical dels alumnes de secundària a través de la recerca i el raonament: l'ús del pronom hi en el català oral. Articles de Didàctica de la Llengua i la Literatura, 31, 99-110.

Camps, A., \& Zayas, F. (coord.) (2006) Secuencias didácticas para aprender gramática. Barcelona: Editorial Graó.

Coronas, R. (2010). Anàlisi comparativa de la coordinació sintàctica. Articles de Didàctica de la Llengua i la Literatura, 50, 27-40.

Decret 142/2007, de 26 de juny, pel qual s'estableix l'ordenació dels ensenyaments de l'educació primària. Currículum: educació primària. Servei d’Ordenació Curricular, juny 2009.

Durán, C. (2008). Parlem del verb amb els alumnes de Secundària. Representacions gramaticals i activitat metalingüística. Departament d'Educació de la Generalitat de Catalunya. [Disponible a: www.xtec.es/sgfp/llicencies/200708/memories/1770m.pdf; consulta: gener 2012]

Eshkol, I. (2005). La construction du concept de verbe. A C. Vaguer, D. Leeman, D, Le verbe dans tous ses états (pp. 17-36). Namur: Presses Universitaires de Namur.

Ferreiro, E. (1971). Les relations temporelles dans le langage de l'enfant. Genève: Droz.

Ferrer, M., \& López, F. (1999). Llibres de text i concreció del currículum de llengua. Articles de Didàctica de la Llengua i De La Literatura,19, 9-23.

Fontich, X. (2006). Hablar y escribir para aprender gramática. Barcelona: Horsori Editorial.

Fontich, X. (2010). La construcció del saber metalingüístic. Estudi sobre l'aprenentatge de la gramàtica d'escolars a secundària en el marc d'una seqüència didàctica. [tesi doctoral; www.tdx.cat/handle/10803/4684; consulta: desembre 2011]

Garitte, C. (2004). Les conditions du verbe: Aspects cognitifs et développementaux. A C. Vaguer, B. \& Lavieu, B. (coords.), Le verbe dans tous ses états (pp. 19-32). Namur. Presses Universitaires de Namur.

Gourdet, P. (2010). L'enseignement du verbe à l'école élémentaire: Caractérisation linguistique et application didactique. A D. Leeman, D. (dir.), Les Cahiers De l'ED 139 Connaissance, Langage, Modélisation (pp. 17-34). Paris: Université Paris Ouest Nanterre la Défense.

Hamon, S. (2005). Les nouvelles syntaxes peuvent-elles etre utiles à la grammaire scolaire. A C. Vaguer, D. Leeman, Le verbe dans tous ses états (pp. 83-102). Namur: Presses Universitaires de Namur.

Lusetti, M. (2008). Le verbe pour commencer la grammaire au CE1. Recherches. L'enseignement De La Langue, 48, 105-135.

Macià, J. (2008). I de les classes de mots, què en saben els nostres alumnes? Articles de Didàctica de la Llengua i la Literatura, 45, 61-76.

Mann, S. (2011). A critical review of qualitative interviews in applied linguistics. Applied Linguistics, 32, 6-24.

Milian, M. (2005). Parlar per fer gramàtica. Articles de Didàctica de la llengua i la literatura, $37,11-30$.

Milian, M. (2010). La gramática en los manuales de lengua: ¿qué actividades se proponen a los alumnos?. A T. Ribas (coord.), Libros de texto y enseñanza de la gramática (pp. 155-172). Barcelona: Graó.

Mondada, L. (2002). Construction des objets de discours et catégorisation: une approche des processus de référenciation. Rev. de letras, 24, 118-130.

Notario, G. (2000). Conceptos gramaticales en alumnos de $4^{o}$ de ESO. El sujeto. Treball d’investigació de 3r cicle. Universitat Autònoma de Barcelona. Treball no publicat. 
Petit, G. (2004). La représentation du verbe dans les manuels de français pour le primaire. A A. Vaguer, \& B. Lavieu (dirs.), Le verbe dans tous ses états (pp. 51-78). Namur: Presses universitaires de Namur.

Quet, F., \& Dourojeanni, D. (2004). En cycle III, repérer le verbe. Langue Et Études De La Langue. Approches Linguistiques Et Didactiques, 301-310.

Real Academia Española (2009). Nueva gramática de la lengua española. Madrid: EspasaCalpe.

Ribas, T. (2010). Aprender sobre el verbo en cuatro lenguas. Análisis de la noción de verbo en cuatro manuales de lenguas distintas de $3^{\circ}$ de ESO. A T. Ribas, T. (coord.), Libros de texto y enseñanza de la gramática (pp. 55-75). Barcelona: Graó.

Roubaud, M.N., \& Touchard, Y. (2004). Vers la notion de verbe: De l'approche intuitive à la construction du savoir. Langue Et Études De La Langue. Approches Linguistiques Et Didactiques, 257-267.

Ruiz Bikandi, U. (2010). El conocimiento sobre la lengua en el Decreto de Enseñanzas Mínimas de 2007. Una revisión crítica. A T. Ribas (coord.), Libros de texto y enseñanza de la gramática (pp. 33-54). Barcelona: Graó.

Sautot, J., \& Lepoire Duc, S (2009). La grammaire: Un problème pour les élèves, un problème pour le maitre aussi. Repères, 125-142.

Solà, J. (dir.) (2002). Gramàtica del català contemporani. Barcelona: Empúries.

Tió, J . (2007). El primer nou currículum de llengua del segle XXI. Escola Catalana, 42, 6-8.

Torralba, M. (2010). El tractament dels conceptes gramaticals en un llibre de sisè de primària. Articles de Didàctica de la Llengua i la Literatura, 50, 41-56.

Vaguer, C., \& Lavieu, B. (dirs.) (2004). Le verbe dans tous ses états (1). Namur: Presses universitaires de Namur.

Vaguer, C., \& Leeman, D. (2005). Le verbe dans tous états (2). Namur: Presses universitaires de Namur.

\footnotetext{
${ }^{1}$ En la llengua francesa, el verb té una dificultat afegida respecte al català pel que fa a la morfologia, ja que l'oral no permet diferenciar les diferents terminacions, de manera que l'escola focalitza l'atenció en l'escrit des del punt de vista morfològic i ortogràfic. Malgrat tot, també hi ha veus que reclamen que es treballi en la construcció del concepte des d'altres perspectives.

${ }^{2}$ Decret 142/2007, de 26 de juny, pel qual s'estableix l'ordenació dels ensenyaments de l'educació primària. En aquest article, les referències al currículum es fan a partir del document publicat el 2009.

${ }^{3}$ L'article és una part d'una investigació més àmplia sobre el coneixement del temps verbal del present. Aquesta recerca s'inscriu en la línia del GREAL per construir una gramàtica pedagògica del verb.

${ }^{4} \mathrm{~A}$ banda d'explorar quin és el coneixement declaratiu i procedimental de les parelles sobre el verb, l'anàlisi de les converses també es preguntava sobre el reconeixement de diversos valors del present, d'acord amb els objectius de la investigació.

${ }^{5}$ Veure a l'annex la simbologia de la transcripció.

${ }^{6}$ En totes les taules que mostren fragments de les converses, la columna de l'esquerra aporta la informació següent: Par+número indica el número de parella, seguit, entre parèntesis, del curs al qual pertany (3r o 6è). També s’hi inclou el pseudònim dels alumnes, ja que a les transcripcions només se’n mostra la inicial. Com que en tots els casos "I” indica investigadora (veure simbologia de la transcripció), a les taules ja no s’especifica.

${ }^{7}$ Veure Taula 1.

${ }^{8}$ La relació entre totes dues àrees curriculars a propòsit de la noció de temps es tracta en altres parts de la recerca que no es mostren en aquest article.

${ }^{9}$ Veure Taula 1.

${ }^{10}$ Veure Taula 1.

${ }^{11}$ Aquesta constatació es corrobora en altres parts de la recerca de què formen part els resultats que es presenten en aquest article.
} 


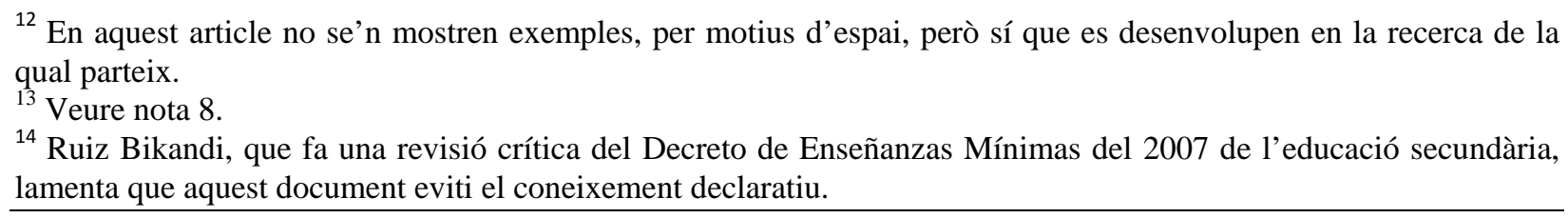

Annex: Simbologia de la transcripció

\begin{tabular}{|l|l|}
\hline \multicolumn{2}{|c|}{ Símbols usats en la transcripció } \\
\hline \multicolumn{1}{|c|}{ Fenomen } & \multicolumn{1}{c|}{ Codificació } \\
\hline $\begin{array}{l}\text { Autor/a del torn: inicial en majúscula del pseudònim del parlant + dos punts (I indica } \\
\text { investigadora) }\end{array}$ & $\begin{array}{l}\text { I: } \\
\text { J: }\end{array}$ \\
\hline Seqüència tonal terminal descendent &. \\
\hline Seqüència tonal terminal ascendent & $?$ \\
\hline Allargament de vocal & $::$ \\
\hline Pausa inferior a tres segons & $:::$ \\
\hline Pausa superior a tres segons & $(\ldots)$ \\
\hline Solapament & $($ segons $)$ \\
\hline Interrupcions & $=$ text= \\
\hline Paraules emfasitzades & Text__ \\
\hline Text llegit & En cursiva \\
\hline Fragment incomprensible & “entre cometes” \\
\hline Comentaris del transcriptor & XXX \\
\hline Assentiment & $($ (comentari) $)$ \\
\hline Dubte & mhm / ha \\
\hline
\end{tabular}

Agraïments: L'autora agraeix a la doctora Marta Milian la lectura i els comentaris de la primera versió d'aquest article, que és una síntesi d’un capítol de la seva tesi doctoral (en curs), dirigida per Milian.

\section{Referència de l'autora:}

Mariona Casas i Deseures és llicenciada en Periodisme per la Universitat Autònoma de Barcelona, en Humanitats per la Universitat Oberta de Catalunya i té el certificat de Professional de la Llengua (K) de la Junta Permanent de Català. Màster de Recerca en Didàctica de la Llengua i la Literatura per la Universitat Autònoma de Barcelona (2008), actualment és professora agregada de didàctica de la llengua i la literatura a la Facultat d’Educació, Traducció i Ciències Humanes de la Universitat de Vic (UVic). Participa en dos grups de recerca: el GREAL (Grup de Recerca sobre Ensenyament i Aprenentatge de Llengües, UAB), en el marc del qual està acabant la tesi doctoral sobre didàctica de la gramàtica (sota la direcció de la doctora Marta Milian) i participa en el projecte "La incidència de la reflexió sobre la llengua en la construcció de la competència escrita” (I+D 2011); i el GRELL (Grup de Recerca en Educació, Llenguatge i Literatura) de la UVic.

\section{Email: mariona.casas@uvic.cat}

Per citar aquest article:

Casas i Deseures, M. (2012). La construcció del coneixement sobre el verb en alumnes de 3r i 6è d’educació primària. Bellaterra Journal of Teaching \& Learning Language \& Literature, 5(2), 43-64. 